\title{
Preventive effect of toothpastes with MMP inhibitors on human dentine erosion and abrasion in vitro
}

Angelica Reis HANNAS ${ }^{1}$, Melissa Thiemi KATO², Cristiane de Almeida Baldini CARDOSO ${ }^{3}$, Ana Carolina MAGALHÃES ${ }^{1}$, José Carlos PEREIRA ${ }^{4}$, Leo TJÄDERHANE${ }^{5}$, Marília Afonso Rabelo BUZALAF ${ }^{1}$

\author{
1- Universidade de São Paulo, Faculdade de Odontologia de Bauru, Departamento de Ciências Biológicas, Bauru, SP, Brasil. \\ 2- Universidade do Sagrado Coração, Departamento de Odontologia, Bauru, SP, Brasil. \\ 3- Universidade do Sagrado Coração, Departamento de Odontopediatria, Bauru, SP, Brasil. \\ 4- Universidade de São Paulo, Faculdade de Odontologia de Bauru, Departamento de Dentística, Endodontia e Materiais Odontológicos, Bauru, SP, Brasil. \\ 5- Oulu University Hospital and University of Oulu, Medical Research Center, Institute of Dentistry, Oulu, Finland.
}

Corresponding address: Marília Afonso Rabelo Buzalaf - Universidade de São Paulo Faculdade de Odontologia de Bauru - Departamento de Ciências Biológicas - Al. Octávio Pinheiro Brisolla, 9-75 - Bauru - SP - 17012-901 - Brazil - Phone: +55 -1432358346 - e-mail: mbuzalaf@fob.usp.br

Submitted: August 25, 2015 - Modification: December 09, 2015 - Accepted: December 11, 2015

\section{ABSTRACT}

\begin{abstract}
$T^{\text {he }}$ he use of gels and mouthrinses with MMP inhibitors (chlorhexidine, and green tea extract) was shown to prevent erosive wear. The aim of this study was to analyze the protective effect of toothpastes containing MMP inhibitors on dentine loss induced by erosion in vitro. Material and Methods: Five groups each containing 12 specimens of human root dentine were prepared. The specimens were subjected to 1 min erosion by immersion in a cola drink, 4 times a day, for $5 \mathrm{~d}$. Each day, after the first and last erosive challenges, the specimens were brushed for $15 \mathrm{~s}$ with a slurry of dentifrice and water (1:3) containing placebo, $1,100 \mathrm{ppm}$ fluoride, $0.61 \%$ green tea extract, $0.12 \%$ chlorhexidine or $0.004 \%$ chlorhexidine (commercial toothpaste). Between the acid challenges, the specimens were stored in artificial saliva with remineralizing potential until the next treatment. Dentine loss was determined using profilometry. Data were analyzed using one-way ANOVA after log transform $(p<0.05)$. Results: The mean wear values $(\mu \mathrm{m})$ were as follows: placebo $1.83 \pm 0.53 ; 0.61 \%$ green tea extract $1.00 \pm 0.21$; fluoride $1.27 \pm 0.43 ; 0.12 \%$ chlorhexidine $1.19 \pm 0.30$; and $0.004 \%$ chlorhexidine $1.22 \pm 0.46$. There was a significant difference in wear between placebo and all the treatment toothpastes, which did not differ from each other. Conclusion: The results suggest that toothpastes containing MMP inhibitors are as effective as those based on $\mathrm{NaF}$ in preventing dentine erosion and abrasion.
\end{abstract}

Keywords: Erosion. Dentin. Matrix metalloproteinases. Inhibitors. Toothpastes.

\section{NTRODUCTI ON}

The reduction in caries prevalence, associated with an increase in tooth-retention rates, has posed new challenges regarding preventive measures in oral health. The augmented consumption of acidic foods and beverages has led to higher occurrence of dental erosion, which is defined as the loss of tooth substance caused by acids $(\mathrm{pH}<4.5)$, undersaturated regarding apatite, in the absence of microorganisms ${ }^{15,22}$. The frequent ingestion of acidic beverages has a profound effect on dentine, especially for adults and for the elderly population. With age, gingival recession is a common occurrence, leading to the subsequent exposure of cement and root dentine that are quite vulnerable to erosion ${ }^{2,13}$.

The exact mechanism of the erosion process in exposed dentine root surfaces is not known. Although the mineral phase of the dentine is lost after the erosive challenge, the fate of the organic phase is not completely understood ${ }^{2,11,29}$. When dentine is exposed to acids, the minerals from the peritubular/intertubular dentine junction are initially extracted. Next, the peritubular dentine is degraded and the dentine tubuli become wider ${ }^{25}$. Finally, a 
superficial layer of demineralized collagenous matrix can be detected. This demineralized organic layer is resistant to mechanic removal by brushing forces up to $4 \mathrm{~N}^{5,8}$, and it is plausible that this outermost layer of collagenous matrix might protect the remaining dentine against mechanical forces, like toothbrush abrasion ${ }^{8}$. It could also limit ionic diffusion into and out of the demineralized surface ${ }^{16,19,21}$. Together, these properties may explain why its maintenance has been attributed to reduce the progression of dentine erosion ${ }^{2,3}$.

It is not known to which extent the protective effect of the demineralized organic matrix is relevant in clinical reality. This layer could be degraded by matrix metalloproteinases (MMPs) 2,10,28, which have been suggested to contribute to the progression of dentine erosion ${ }^{2,11}$. MMP inhibitors, such as chlorhexidine, green tea polyphenols, and $\mathrm{FeSO}_{4}$ in solutions or gels, reduce the dentine erosive wear ${ }^{4,17,18,24}$. However, the use of toothpastes as a vehicle to deliver MMPs to dentine has not been studied so far. This vehicle seems particularly attractive, since toothbrushing with toothpaste is an integral part of daily oral hygiene measures, and the demineralized organic matrix is not removed during this procedure ${ }^{5,8}$. Thus, the present study tested the null hypothesis that toothpastes containing MMP inhibitors do not exert any influence on dentine erosion associated with toothbrush abrasion.

\section{MATERIAL AND METHODS}

\section{Preparation of dentine specimens}

Sixty recently extracted non-carious human third molars were used in this study. The protocol was approved by the Institutional Review Board of Bauru School of Dentistry, University of São Paulo $(011 / 2008)$. Prior to the extraction, the patients were informed about the use of their teeth for research purposes and consent was obtained. Teeth were stored in $0.9 \% \mathrm{NaCl}$ with $0.2 \% \mathrm{NaN}_{3}$ at $4{ }^{\circ} \mathrm{C}$. The crowns were sectioned from the roots with a diamond saw (Isomet 1000; Buehler, Lake Bluff, IL, USA). Dentine slabs $(4 \times 4 \mathrm{~mm})$ were cut from the cervical third of the root under water cooling, mounted on acrylic blocks and ground flat with water-cooled carborundum discs $(320,600$ and 1,200 grades of $\mathrm{Al}_{2} \mathrm{O}_{3}$ papers; Buehler). After each

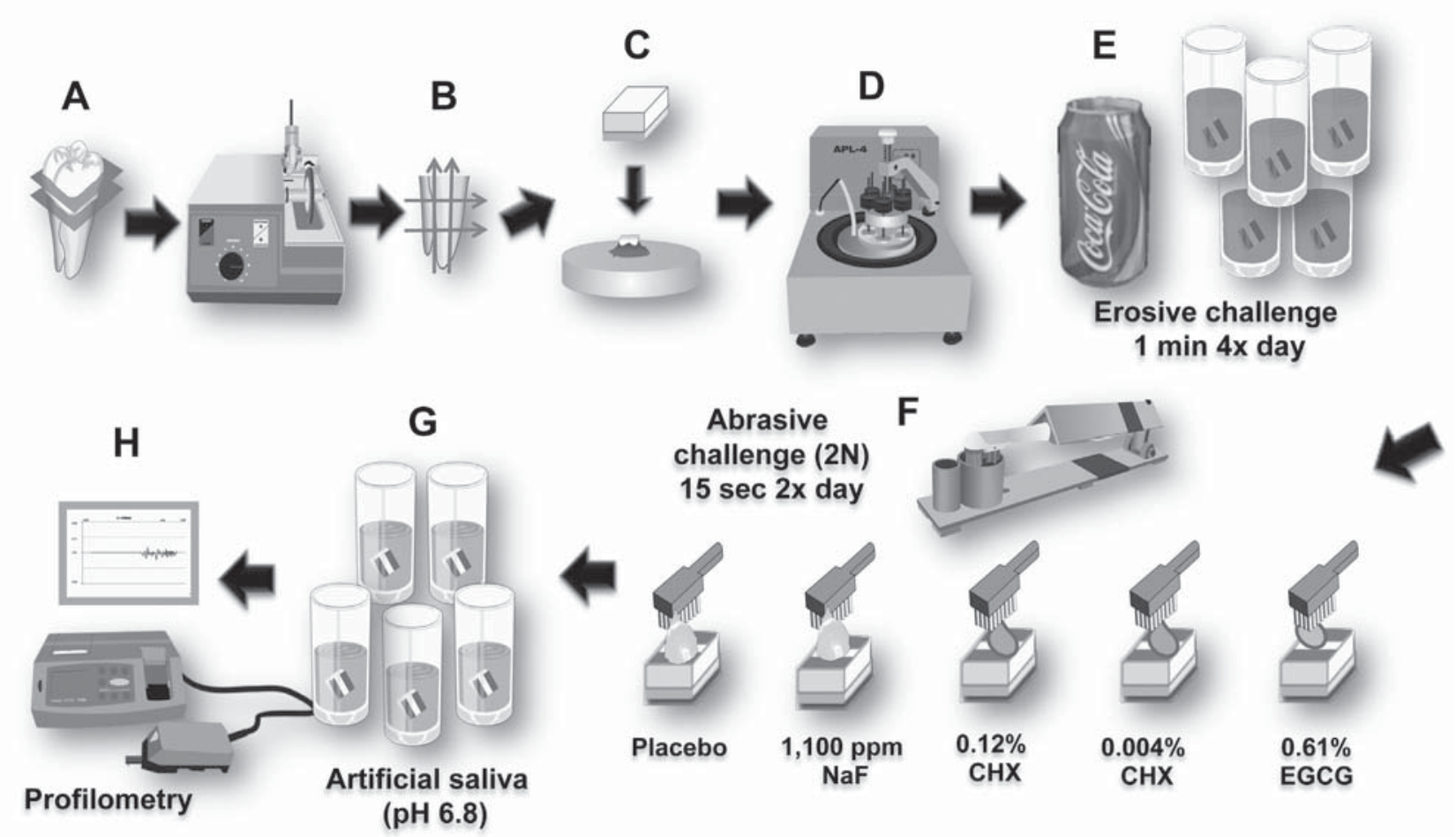

Figure 1- Schematic illustration of the experimental sequence. (A) The crowns were sectioned from the roots with a diamond saw. (B) Dentine slabs $(4 \times 4 \mathrm{~mm})$ were cut from the cervical third of the root human root, (C) fixed on acrylic rods with sticky wax, and (D) the external surfaces were ground flat and polished with water-cooled carborundum discs (320, 600, and 1,200 grades of $\mathrm{Al}_{2} \mathrm{O}_{3}$ papers). Dentine specimens $(\mathrm{n}=12)$ were randomly divided into 5 groups. (E) The specimens were subjected to erosion (1 minute) by immersion in a cola drink, 4 times a day, for $5 \mathrm{~d}$. (F) After the first and last erosive challenges, the specimens were brushed for $15 \mathrm{~s}$ with slurry of dentifrice and water (1:3) with the following treatment toothpastes: placebo; $1,100 \mathrm{ppm} \mathrm{F}$ as NaF; $0.61 \%$ green tea extract (EGCG); $0.12 \%$ chlorhexidine (CHX); $0.004 \%$ chlorhexidine $(\mathrm{CHX})$. $(\mathrm{G})$ The specimens were then stored in artificial saliva until the next treatment. $(\mathrm{H})$ Dentine alterations were determined using profilometry 
disc, the specimens were cleaned in ultrasound bath (T7 Thornton, Unique Ind. e Com. Ltda., São Paulo, $\mathrm{SP}$, Brazil) for $2 \mathrm{~min}$. Finally, the specimens were polished with felt paper wet by diamond spray ( 1 $\mu \mathrm{m}$; Buehler) on a rotating polishing machine. The specimens were randomly assigned into five groups of 12 specimens each that differed according to the type of toothpaste used. Sample size was calculated based on a previous study ${ }^{26}$. In order to establish reference surfaces for lesion depth determination, two layers of nail varnish (Risqué: Niasi Indústria de Cosméticos LTDA, Taboão da Serra, SP, Brazil) were applied on each side of the surface of each specimen, leaving $1 \mathrm{~mm}$ of the middle unprotected (Figure 1).

\section{Treatment protocol}

For erosive demineralization, each specimen was immersed in $30 \mathrm{~mL}$ of Coke $^{\circledR}$ (Cia de Bebidas I piranga, Ribeirão Preto, SP - Brazil, pH 2.6) for 1 min, 4 times a day, during $5 \mathrm{~d}$. Between the demineralization phases, the samples were stored in artificial saliva ${ }^{20}$ containing $0.2 \mathrm{mM}$ glucose, $9.9 \mathrm{mM}$ $\mathrm{NaCl}, 1.5 \mathrm{mM} \mathrm{CaCl}_{2} .2 \mathrm{H}_{2} \mathrm{O}, 3 \mathrm{mM} \mathrm{NH}_{4} \mathrm{Cl}, 17 \mathrm{mM} \mathrm{KCl}$, $2 \mathrm{mM} \mathrm{NaSCN}, 2.4 \mathrm{mM} \mathrm{K}_{2} \mathrm{HPO}_{4}, 3.3 \mathrm{mM}$ urea, 2.4 $\mathrm{mM} \mathrm{NaH} \mathrm{PO}_{4}$, and traces of ascorbic acid ( $\mathrm{pH}$ 6.8) at $37^{\circ} \mathrm{C}$ for 59 min to allow remineralization. Each day, following the first and last erosive challenges, brushing was performed for $15 \mathrm{~s}$ per specimen using powered toothbrush with 166 oscillations/s
(Oral- ${ }^{\circledR}{ }^{\circledR}$, Cross Action Power, Procter \& Gamble, Cuajimalpa, Mexico). For standardized brushing force, a custom-made device was used, allowing for a pressure of approximately $2 \mathrm{~N}^{32}$. The brushing heads were renewed after 2.5 days of treatment. For each specimen, brushing was performed with 1 $\mathrm{mL}$ of a $1: 3(\mathrm{w} / \mathrm{v})$ slurry of toothpaste and deionized water (Figure 1). Placebo toothpaste gel was prepared with the same composition and $\mathrm{pH}$ (7.0) of the other experimental toothpastes and with no active compound. I ts composition included ethanol, water, sorbitol, glycerine, carboxymethylcellulose, xanthan gum, poliethyleneglycol 400, methylparaben, propylparaben, silicon dioxide, abrasive silicon dioxide, sodium lauryl sulphate, cocoamidopropylbetain, sodium saccharine, mint essence, and orthophosphoric acid. This also served as the base for the experimental gels. Three experimental toothpastes with a similar composition and $\mathrm{pH}$ (7.0) were prepared, with the exception of the compound tested, as follows: 1,100 ppm fluoride (as NaF, Sigma, Steinheim, Germany), 0.61\% green tea extract (OM24, 100\% Camellia sinensis-leaf extract with $30 \pm 3 \%$ catechin; Omnimedica, Schlieren, Switzerland), $0.12 \%$ chlorhexidine digluconate (Sigma). Commercial toothpaste containing $0.004 \%$ chlorhexidine digluconate (Elgydium, Pierre Fabre, Switzerland, $\mathrm{pH}$ 7.0) was also tested (Figure 1). After completion of the 5-day brushing, the specimens were rinsed

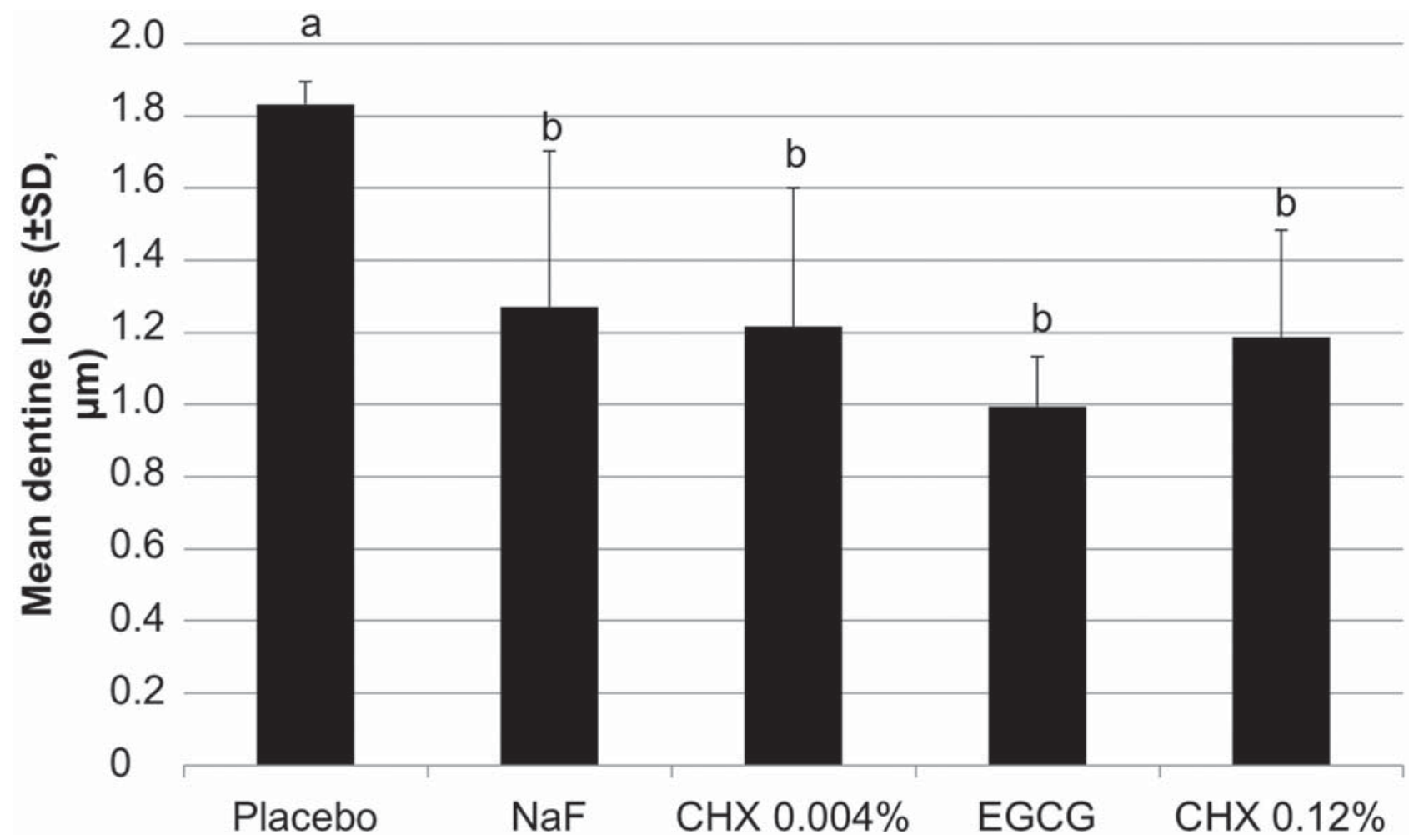

Figure 2- Mean loss of dentine ( \pm standard deviation) in groups submitted to erosive and abrasive challenges in vitro, treated with toothpastes containing MMP inhibitors or fluoride. Distinct letters indicate significant difference among the toothpastes (ANOVA after log transform, $\mathrm{p}<0.05$ ) 
with deionized water and stored in artificial saliva until analyzed (Figure 1).

\section{Dentine loss assessment}

The nail varnish over the surfaces was carefully removed with a scalpel. The specimens were maintained wet to avoid shrinkage. Dentine tissue loss $(\mu \mathrm{m})$ was quantitatively determined by a contact profilometer (Mahr Perthometer, Mahr, Göttingen, Germany) as described before ${ }^{3}$. Briefly, the specimens were slightly dried, gently removing only the excess of water with filter paper, and immediately analyzed. The diamond stylus was moved from one reference area to another across the exposed area $(2.5 \mathrm{~mm}$ length and 2.0 $\mathrm{mm}$ width), recording the profile with a computer program (Software Mahr Surf XT20, Mahr). Five profile measurements were performed in the center of each specimen at intervals of $0.5 \mathrm{~mm}$. The vertical distance between the midpoints of regression lines on the reference and experimental areas was defined as tissue loss $(\mu \mathrm{m})$. The accuracy of the method, evaluated in previous studies, is around $0.5 \mu \mathrm{m}$.

\section{Statistical analysis}

After checking for equality of variances and normal distribution of errors, data were analyzed by one-way ANOVA and Tukey's test after log transformation. The software GraphPad Instat for Windows version 3.0 ( La J olla, CA, USA) was used. The significance level was set at $5 \%$.

\section{RESULTS}

The mean $( \pm S D)$ dentine loss $(\mu \mathrm{m})$ found for the specimens treated with the placebo toothpaste $(1.83 \pm 0.53)$ was significantly higher $(F=5.353$, $p=0.008$ ) than the values found for the specimens from the toothpastes containing MMP inhibitors $(1.00 \pm 0.21,1.19 \pm 0.30$, and $1.22 \pm 0.46$ for $0.61 \%$ green tea extract, $0.12 \%$ chlorhexidine or $0.004 \%$ chlorhexidine, respectively) or fluoride (1.27 \pm 0.43$)$. The toothpastes containing active compounds, however, were not significantly different from one another (Figure 2).

\section{DISCUSSION}

The study design aimed to simulate the habits of patients with erosive lesions. The total dentine erosion time was 20 min with storage in remineralizing solution between the acidic challenges to allow clinically relevant remineralization. The total abrasion time throughout the study was 2.5 min, which would correspond to 30 brushings of $5 \mathrm{~s}$ each for one tooth in the clinical condition ${ }^{31}$. Despite the experimental in vitro conditions employed in an attempt to resemble as closely as possible the clinical condition, some situations could not be reproduced by our protocol, such as the presence of the acquired pellicle, the dynamic salivary flow, the presence of bacteria, as well as variations in temperature. In addition, the concentration of the actives used in the experimental dentifrices $(0.61 \%$ green tea extract and $0.12 \%$ chlorhexidine digluconate) had a good effect on the reduction in dentine erosion when added to rinse solutions in a previous in situ study ${ }^{24}$.

The rate of loss in dentine reduces along time if the demineralized organic matrix is not removed ${ }^{3,6}$. The demineralized collagen layer works as a diffusion obstacle, which occurs also in root caries ${ }^{27}$. It has also been speculated that this organic layer may present buffering capacity. During an erosive challenge from the outer surface, it may adsorb $\mathrm{H}^{+}$, therefore protecting the inner dentine from $\mathrm{pH}$ decrease $\mathrm{e}^{2,19}$. The presence and maintenance of the organic dentine matrix, through the inhibition of collagenolytic enzymes present in dentine and saliva, is required for the remineralization of eroded dentine $\mathrm{i}^{12,30}$. As far as we know, this is the first study to assess the effect of toothpastes with MMP inhibitors on dentine loss and the second in vitro study to show that dentinal enzymes have a role in erosion progression ${ }^{1}$. Most of the previous studies have been performed in situ, in which the potential role of salivary MMPs cannot be differentiated from the dentinal MMPs. Since demineralized dentine organic matrix seems to be quite resistant to mechanical forces, even under high brushing forces $^{7}$, avoiding its degradation by employing MMP inhibitors has emerged as a promising method to prevent dentine erosion. This approach has been tested by using rinses and gels as vehicles to deliver MMP inhibitors ${ }^{17,18,24}$. However, even though fluoride toothpastes are widely tested to prevent dental erosion $^{23}$, to our knowledge, they have never been used as vehicles to deliver MMP inhibitors to the dental structure.

The results of the present investigation demonstrated that toothpastes with chlorhexidine or green tea extract are able to decrease dentine loss under mild in vitro erosive and abrasive conditions. Additionally, they were at least as effective as conventional toothpaste with 1,100 ppm F. Both chlorhexidine and green tea catechins are MMP inhibitors ${ }^{4,9,24}$ with unknown remineralizing potential. As a matter of fact, while both hesperidin (a citrus fluid flavonoid) and chlorhexidine reduced the collagenase-induced loss of mineral and erosive lesion progression, only hesperidin was able to induce mineral uptake in a recent study ${ }^{14}$. The present investigation supports previous studies with reduced dentine erosion using different MMP inhibitors with distinct vehicles ${ }^{17,18,24}$, and 
further indicates the distinctive role of MMPs in the progression of dentine erosion. Thus, the null hypothesis was rejected.

In the present study, the toothpastes tested contained MMP inhibitors or fluoride. However, since the effect of fluoride to prevent dentine erosion has been suggested to be dependent on the maintenance of the demineralized organic matrix $x^{2,7,16,30}$, it would be interesting to test toothpastes containing both MMP inhibitor(s) and fluoride. It is important to highlight that the efficacy of MMP inhibitors to prevent dentine erosion seems to be dependent on the vehicle used to deliver these inhibitors. The single application of gels ${ }^{17}$ is more effective than multiple rinses ${ }^{24}$ under similar erosive protocols. In fact, this application of gels containing EGCG or chlorhexidine completely prevented dentine erosion under erosive challenges conducted in situ/ex vivo (100 min of erosion $)^{17}$. However, when the erosive challenges were conducted for $10 \mathrm{~d}$ (200 min of erosion), some degree of dentine loss occurred (Kato, et al., unpublished observations). Thus it seems that even in the best case scenario, repeated MMP inhibitor applications are needed for permanent prevention. This would be easier to achieve with the daily oral hygiene products, especially toothpastes, with MMP-inhibiting action.

\section{CONCLUSI ON}

In conclusion, under the limitations of this in vitro study, toothpastes containing MMP inhibitors $(0.12 \%$ or $0.004 \%$ chlorhexidine, or $0.61 \%$ green tea extract) were able to prevent dentine wear caused by erosion and abrasion. They performed similarly to the toothpaste containing $1,100 \mathrm{ppm}$ fluoride, which was able to partially reduce dental erosion. Since MMP inhibition has also been suggested as a strategy to reduce dentine caries progression ${ }^{28,30}$, toothpaste with MMP inhibiting action combined with fluoride might be effective in the protection of the two most common reasons for the loss of tooth structure, caries and erosion. However, these results should be confirmed in further in situ and clinical studies.

\section{ACKNOWLEDGEMENTS}

This study was funded by CNPq (Grant no. $557863 / 2008-2)$. The funders had no role in study design, data collection and analysis, decision to publish, or preparation of the manuscript.

\section{REFERENCES}

1- Barbosa CS, Kato MT, Buzalaf MA. Effect of supplementation of soft drinks with green tea extract on their erosive potential against dentine. Austr Dent J. 2011;56(3):317-21.

2- Buzalaf MA, Charone S, Tjäderhane L. Role of hostderived proteinases in dentine caries and erosion. Caries Res. 2015; 49(Suppl 1):30-7.

3- Comar LP, Cardoso CA, Charone S, Grizzo LT, Buzalaf MA, Magalhães AC. TiF4 and NaF varnishes as anti-erosive agents on enamel and dentin erosion progression in vitro. J Appl Oral Sci. 2015;23(1): 14-8.

4- Demeule $M$, Brossard $M$, Pagé $M$, Gingras $D$, Béliveau R. Matrix metalloproteinase inhibition by green tea catechins. Biochim Biophys Acta. 2000; 1478(1):51-60.

5- Ganss C, Hardt M, Blazek D, Klimek J, Schlueter N. Effects of toothbrushing force on the mineral content and demineralized organic matrix of eroded dentine. Eur J Oral Sci. 2009; 117(3):25560.

6- Ganss C, Klimek J, Starck C. Quantitative analysis of the impact of the organic matrix on the fluoride effect on erosion progression in human dentine using longitudinal microradiography. Arch Oral Biol. 2004; 49(11): 931-5.

7- Ganss C, Lussi A, Sommer N, Klimek J, Schlueter N. Efficacy of fluoride compounds and stannous chloride as erosion inhibitors in dentine. Caries Res. 2010;44(3):248-52.

8- Ganss C, Schlueter N, Hardt M, von Hinckeldey J, Klimek J. Effects of toothbrushing on eroded dentine. Eur J Oral Sci. 2007; 115(5): 390-6.

9- Gendron R, Grenier D, Sorsa T, Mayrand D. Inhibition of the activities of matrix metalloproteinases 2,8 , and 9 by chlorhexidine. Clin Diagn Lab Immunol. 1999;6(3):437-9.

10- Hannas AR, Pereira J C, Granjeiro J M, Tjäderhane L. The role of matrix metalloproteinases in the oral environment. Acta Odontol Scand. 2007;65(1): 1-13.

11- Hara AT, Ando M, Cury JA, Serra MC, González-Cabezas C, Zero DT. Influence of the organic matrix on root dentine erosion by citric acid. Caries Res. 2005; 39(2): 134-8.

12- Hara AT, Karlinsey RL, Zero DT. Dentine remineralization by simulated saliva formulations with different $\mathrm{Ca}$ and $\mathrm{Pi}$ contents. Caries Res. 2008;42(1):51-6.

13- Hara AT, Lussi A, Zero DT. Biological factors. Monogr Oral Sci. 2006; 20: 88-99.

14- Hiraishi N, Sono R, Islam MS, Otsuki M, Tagami J, Takatsuka $T$. Effect of hesperidin in vitro on root dentine collagen and demineralization. J Dent. 2011;39(5):391-6.

15- Jaeggi T, Lussi A. Prevalence, incidence and distribution of erosion. Monogr Oral Sci. 2006; 20:44-65.

16- Kato MT, Bolanho A, Zarella BL, Salo T, Tjäderhane L, Buzalaf MA. Sodium fluoride inhibits MMP-2 and MMP-9. J Dent Res. 2014; 93(1): 74-7.

17- Kato MT, Leite AL, Hannas AR, Buzalaf MA. Gels containing MMP inhibitors prevent dental erosion in situ. J Dent Res. 2010;89(5): 468-72.

18- Kato MT, Leite AL, Hannas AR, Oliveira RC, Pereira JC, Tjäderhane $L$, et al. Effect of iron on matrix metalloproteinase inhibition and on the prevention of dentine erosion. Caries Res. 2010; 44(3): 309-16.

19- Kleter GA, Damen JJ, Everts V, Niehof J, Ten Cate JM. The influence of the organic matrix on demineralization of bovine root dentin in vitro. J Dent Res. 1994; 73(9):1523-9.

20- Klimek J, Hellwig E, Ahrens G. Fluoride taken up by plaque, by the underlying enamel and by clean enamel from three fluoride compounds in vitro. Caries Res. 1982;16(2):156-61.

21- Klont B, ten Cate J M. Remineralization of bovine incisor root lesions in vitro: the role of the collagenous matrix. Caries Res. $1991 ; 25(1): 39-45$.

22- Lussi A, Hellwig E, Zero D, Jaeggi T. Erosive tooth wear: diagnosis, risk factors and prevention. Am J Dent. 2006; 19(6):31925. 
23- Magalhães AC, Wiegand A, Buzalaf MA. Use of dentifrices to prevent erosive tooth wear: harmful or helpful? Braz Oral Res. 2014;28(Sp Iss): $1-6$.

24- Magalhães AC, Wiegand A, Rios D, Hannas A, Attin T, Buzalaf MA. Chlorhexidine and green tea extract reduce dentin erosion and abrasion in situ. J Dent. 2009; 37(12): 994-8.

25- Meurman JH, Drysdale T, Frank RM. Experimental erosion of dentin. Scand J Dent Res. 1991;99(6):457-62.

26- Moron BM, Miyazaki SS, Ito N, Wiegand A, Vilhena F, Buzalaf $M A$, et al. Impact of different fluoride concentrations and $\mathrm{pH}$ of dentifrices on tooth erosion/abrasion in vitro. Aust Dent J. 2013; 58(1): 106-11.

27- Ogaard B, Rolla G, Arends J. In vivo progress of enamel and root surface lesions under plaque as a function of time. Caries Res. 1988; 22(5):302-5.
28- Sulkala M, Wahlgren J, Larmas M, Sorsa T, Teronen O, Salo T, et al. The effects of MMP inhibitors on human salivary MMP activity and caries progression in rats. J Dent Res. 2001;80(6):1545-9. 29- Tjäderhane L, Buzalaf MA, Carrilho M, Chaussain C. Matrix metalloproteinases and other matrix proteinases in relation to cariology: the era of "dentin degradomics". Caries Res. 2015; 49(3): 193-208.

30- Tjäderhane L, Sulkala M, Sorsa T, Teronen O, Larmas M, Salo T. The effect of MMP inhibitor metastat on fissure caries progression in rats. Ann N Y Acad Sci. 1999; 878:686-8.

31- Wiegand A, Attin T. Design of erosion/abrasion studies insights and rational concepts. Caries Res. 2011;45:53-9.

32- Wiegand A, Kowing L, Attin T. Impact of brushing force on abrasion of acid-softened and sound enamel. Arch Oral Biol. 2007; 52(11): 1043-7. 